\title{
Changing patterns of weathering and erosion across rapid climate change events - evidence from lithium isotopes
}

PHILIP A E POGGE VON STRANDMANN ${ }^{1,2}$, DR. DAVID J WILSON $^{3}$, ALEXANDER J. KRAUSE ${ }^{4}$, CHUNYAO LIU ${ }^{4}$ AND XIANYI LIU ${ }^{4}$

${ }^{1}$ University of Mainz

${ }^{2}$ JGU Mainz

${ }^{3}$ London Geochemistry and Isotope Centre (LOGIC), Institute of Earth and Planetary Sciences, University College London and Birkbeck, University of London

${ }^{4} \mathrm{UCL}$

Presenting Author: ppoggevo@uni-mainz.de

Chemical weathering exerts a fundamental control on longterm climate, by removing atmospheric $\mathrm{CO}_{2}$. However, the weathering regime (i.e., the balance between chemical weathering and physical erosion) strongly modifies how the weathering system responds to climate change, and therefore how rapidly it can mitigate climate change.

Lithium isotopes provide a tracer of silicate weathering regime, because clay formation causes isotope fractionation, meaning that residual surface waters become isotopically heavy. Clay formation can potentially inform on $\mathrm{CO}_{2}$ sequestration efficiency, as continental clay formation can inhibit the transport of relevant cations $(\mathrm{Ca}, \mathrm{Mg})$ to the oceans, where they would sequester $\mathrm{CO}_{2}$.

Here we will show how $\mathrm{Li}$ isotopes partition between solution and different secondary solid phases (exchangeable fraction, oxides, and clays) in the modern weathering environment and in laboratory experiments. These phases can modify the Li isotope signal that eventually is transported to the oceans, where it can be recorded in both carbonate and silicate marine archives.

We will then explore Li isotope records across several rapid warming periods, dominantly during the Cenozoic, such as the Palaeocene-Eocene Thermal Maximum (PETM), the Middle Eocene Climatic Optimum (MECO), and the Middle Miocene Climatic Optimum (MMCO). For all these time periods, the continent-derived Li isotope signal changes, indicating not only a change in the weathering rate, but also a change in the balance of weathering to erosion that may have affected the ability and rate of climatic recovery. 